\title{
Sorgen Sie für sich
}

_ Kürzlich hatte ich das Vergnügen, an einem Seminar für Führungskräfte teilzunehmen. Das Thema der zwei Tage lautete „Gesundes Führen: Stress Glück - Wertschätzung“. Ich kann von Glück sprechen, dass ich die Möglichkeit hatte. Denn seither hat sich einiges bei mir geändert. Ich atme mehrmals am Tag bewusst tief durch und ermögliche so meinem Körper kurze Momente der Entspannung. Ich schaue nicht mehr so sehr auf die Probleme, sondern eher, wie wir diese lösen können.

_ Vor allem versuche ich, bei Konflikten meinen Blick auf ungestillte Bedürfnisse der Beteiligten zu lenken. Gelingt mir das, und ich spreche meine Vermutung aus, löst sich der Zwist schneller auf. Mein Aha-Erlebnis. Im Seminarskript steht treffend formuliert: Was ist ein Konflikt? Zwei wichtige Bedürfnisse, die (wenigstens scheinbar) nicht miteinander vereinbar sind. Zudem ist zu lesen: Gesundes Führen bedeutet, Bedürfnisse und Werte zu hören. Wobei nicht damit gemeint ist, immer alle zu erfüllen. Bei manchen ist es leider einfach nicht möglich oder wäre gesundheitsschädlich, zum Beispiel das grenzenlose Verlangen nach Schokolade.

_ Für Ergotherapeutinnen und Ergotherapeuten gehört das Arbeiten mit Konflikten zum Alltag, gerade auch in der Psychiatrie. Der Artikel „Über'n Berg" auf Seite 18 zeigt sehr einfühlsam, wie schwer es Menschen mit Essstörungen fällt, ihre Konflikte nicht auf dem Teller auszutragen, sondern für sich zu sorgen und ihre Bedürfnisse zu äußern. Und wie gut es tut, wenn dies in einer vertrauensvollen Gruppe gelingt. Es braucht eine gehörige Portion Mut, zu äußern, was einem wichtig ist. Doch es lohnt sich - für alle.

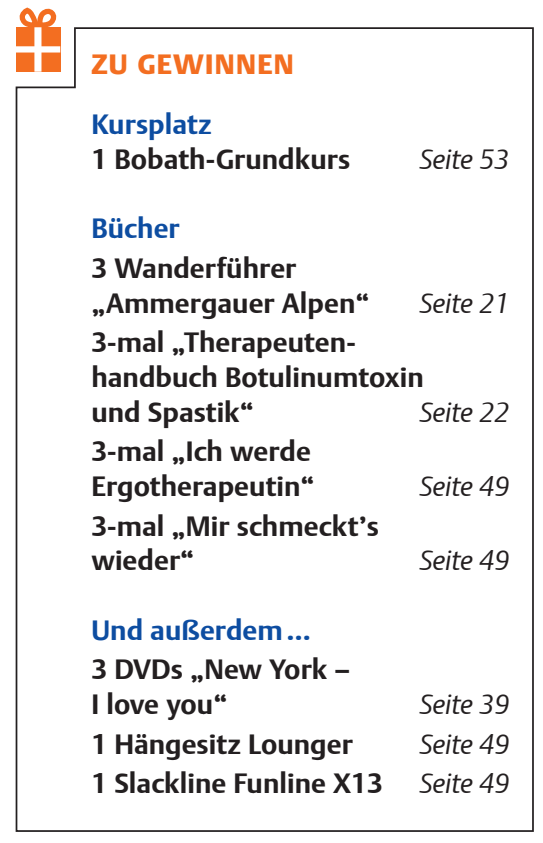

Herzlich Ihre
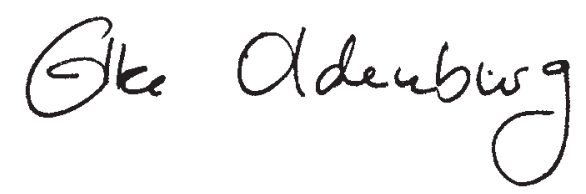

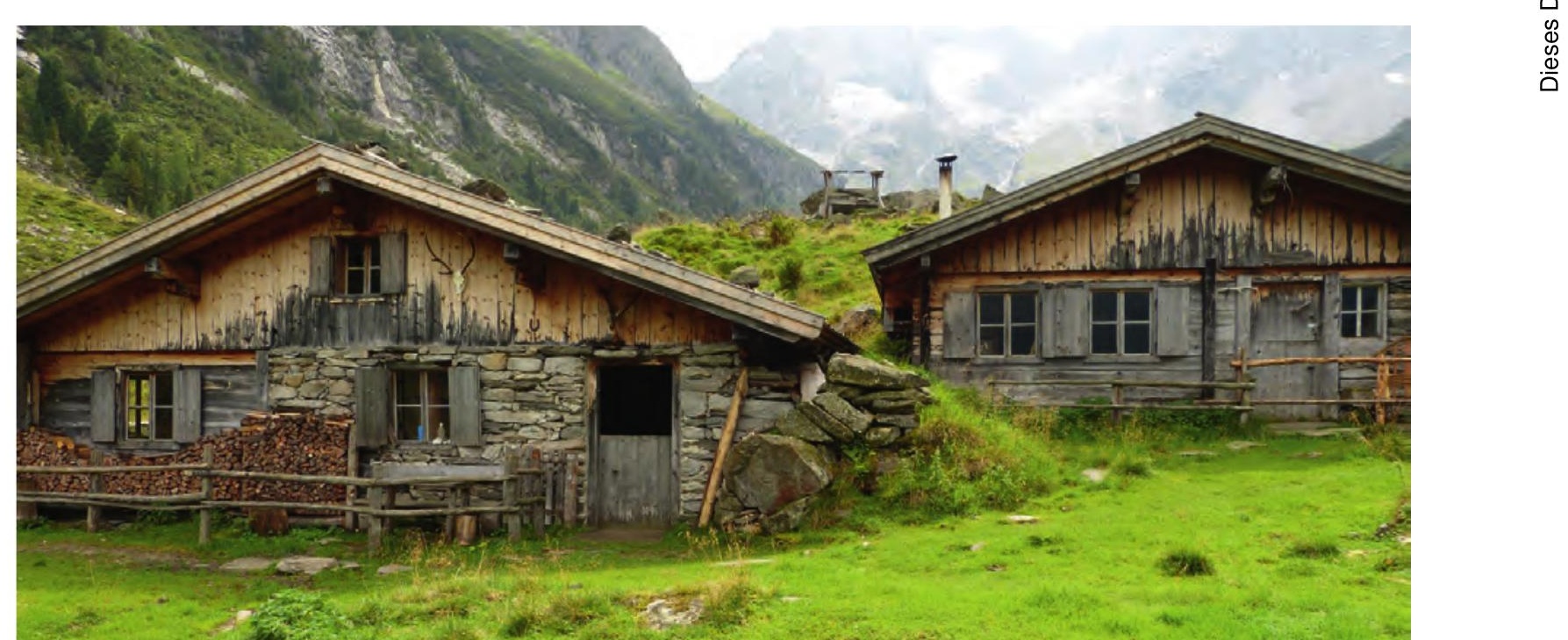

